\title{
STUDENTS LEARNING TO LEARN THROUGH DESIGN
}

\author{
Ken Tallman \\ University of Toronto \\ k.tallman@utoronto.ca
}

\begin{abstract}
Research being conducted in an engineering capstone design course analyzes student creativity and its connection to metacognition. Data collected from questionnaires, video recordings, and interviews will attempt to show that creativity in the design process and metacognitive understanding of creative activity are important factors in successful engineering design.

Motivation for this research comes from the observation that undergraduate engineering students, including those in senior years, have difficulty explaining their design processes. They often have limited understanding of their creative accomplishments as well as a limited ability to explain what makes their approach distinctive or effective.
\end{abstract}

Future research will build on the methodology described here, including a more explicit framework for identifying and assessing creativity in engineering design.

Keywords: Engineering, Creativity, Metacognition, Design,

\section{INTRODUCTION}

This paper explores the relationship between creativity and metacognition in design projects for two teams of students in an undergraduate engineering capstone design course. In particular, the paper presents the preliminary results of current research and assesses its effectiveness.

During the research period, September 1, 2015 through April 30, 2016, I observed and interacted with two teams of students in APS490Y: Multidisciplinary Capstone Design Project. Both teams of students, five members in each team, volunteered to participate in my research project with the understanding that their identities would remain anonymous and that their grades in this or any other course would not be affected. One month into the project, one student decided not to participate in the research project.

From the outset, I wanted to keep the sample size small so as to focus on assessing the effectiveness of my approach: Am I asking the right questions? Did I explore in productive areas? How can I improve my methodology in the future?
For this research project, I distributed two questionnaires to each student, I video recorded two meetings of each team, and I conducted individual interviews with each of the students.

I initially intended that this research focus solely on tracking the students' creative activity during the design project; however, once the project began I recognized the importance of expanding this focus to include tracking the students' metacognitive understanding of their creative activities. My reasoning for this addition was twofold. First, I recognized an intrinsic connection between creativity and metacognition, which I will detail below; secondly, I recognized that to create student interest in this research project, I needed to offer the students a takeaway of their own. Thus, when recruiting teams, I suggested to the students that they would come away from participating in my research project with an enhanced understanding of their approach to design, a skill set that would be useful in the short term for their Portfolio Assignment, worth $20 \%$ of the course grade, and of value in the long term as they advance into the job market or graduate studies.

Creativity is commonly connected to design $[6,8,18]$ and is linked to many of the graduate attributes required by the Canadian Engineering Accreditation Board (CEAB), most notably problem analysis, investigation, and design. Creativity has many dimensions, and is defined somewhat differently in different fields. From psychology, Herbert Simon presents creativity as a logical problem-solving tool [15], while Sarnoff Mednick and Dean Keith Simonton pay close attention to the power of chance and associative thinking, as well as to the role of the subconscious and unconscious, in creative activity $[13,16]$. Recent engineering studies of creativity have followed Teresa Amabile's scholarship [6]. Amabile, originally a chemist and now a professor of business administration, sees creativity as the production of ideas that are both novel and appropriate. The ideas must be new, different in some way from anything preceding them, but they must be suitable to the problem or the situation at hand [1]. Elsewhere, Amabile is perhaps more concrete, stating that creativity must also be useful [2]. This provision, connecting creativity to utility, is of value to my research and to any research on engineering design, 
as it joins ideas to implementation and implementation strategies.

Metacognition, the other skill set being explored in this research, is often referred to as thinking about thinking, the monitoring of cognition [9]. It is also discussed in relation to reflective thinking [20] and to listening to one's inner voice [17]. In relation to the CEAB graduate attributes, metacognition is most closely linked to lifelong learning, the attribute connected to our students' abilities to address their educational needs as they grow as learners.

Metacognition warrants our attention because of its close connection to successful, sustainable creative activity. John Flavell, an authority on cognitive and metacognitive growth in children, argues that metacognitive knowledge can have important effects on the cognitive enterprises of children and adults, leading both to create new goals, as well as to reject or modify old ones [9].

More recently, in an engineering context, Shanna Daly makes an explicit connection between metacognition and creativity in the teaching of engineering design [6]. Daly, using a framework developed by Donald Treffinger, President of the Center for Creative Learning, presents creative learning as a four-part process: 1) Generating ideas, 2) Digging deeper into ideas, 3) Openness and courage to explore ideas, and 4) Listening to one's inner voice. If the first two activities are primarily cognitive, the last, listening to one's inner voice, is primarily metacognitive, the part of the creative process that requires us to reflect on our activities and modify them accordingly. As Daly notes, this kind of cognitive monitoring is essential to successful design [6].

\section{DATA COLLECTED}

From the outset, I wanted to keep the data to a minimum. I made this decision because this research is at a preliminary stage and is aimed as much at testing the data as it is in interpreting its results. Also, and equally importantly, I suspected that if I asked too much of the students I would receive little interest or support from them.

For this research project, I distributed two questionnaires to each student, one at the beginning of the course and one at the end of the course; I video recorded two team meetings, one in the fall term and one in the winter term; and I conducted individual interviews with each of the students, the interviews taking place approximately two weeks after the second video recordings had been completed

\subsection{Entry Questionnaire}

After signing consent forms to participate in the research project, each student completed a questionnaire.
Students submitted the completed questionnaires by email.

\subsection{Video Recordings}

I video recorded each team on two occasions, trying to capture crucial moments in both the early and late stages of the design process. I used two cameras, and I left the room once the meetings began, returning at the end of the meetings to collect the cameras. By being as unobtrusive as possible, I hoped the students would feel less pressure to perform while being recorded. The shortest meeting was 70 minutes, and the longest meeting lasted 120 minutes.

\subsection{Interviews}

In the winter term, approximately two weeks after the second video recordings had been completed, I interviewed each student individually.

One week before the interviews, I gave each student a USB key with the complete video recordings of both of their recorded team meetings. When I gave the students the USB keys I told them to watch as much as they desired and that I would contact them soon with more details.

Approximately four days before the interviews I contacted the students requesting that they be sure to view selected sections of the videos, as I wanted to discuss these sections in our interviews. With Team One, as I named them, I asked all team members to view a 90second sequence from a late October 2015 meeting and a three-minute sequence from a February 2016 meeting. I asked Team Two to preview one 10-minute sequence from their late October 2015 meeting. I did not ask Team Two to view any sequences from their second recorded meeting, as two of the team members were absent from the second team meeting.

Each of the individual interviews lasted approximately one hour. I began each interview by telling the student that I was making an audio recording of the interview and that I would send the audio file to the student shortly. Each interview took a slightly different direction, but in each I asked all students the same set of core questions. (See 3.3 for the list of questions.)

\subsection{Closing Questionnaire}

All of the APS490 teams presented their final designs at a design fair on March 24, 2016. All students then had to submit an individual portfolio on April 10, discussing and reflecting upon their contributions to their team's project. On April 11, one day after students had submitted their portfolio assignments, I sent out the closing questionnaire. In this questionnaire, I asked some 
questions that matched the ones I had asked at the beginning of the course as well as new questions, requiring the students to reflect on their experiences in the course. (See 3.4 for the list of questions.)

\section{SUMMARY OF DATA COLLECTED}

Some data, particularly the video recordings and interviews, still need to be transcribed and coded. However, the results from other data, most specifically the questionnaires, are easier to present here in an unprocessed and uncoded manner.

\subsection{Entry Questionnaire Results}

\section{Question 1: What is your definition of creativity?}

All nine participating students included the word "new" when responding to this question.

For three, there was a sense that creativity happens above and beyond normal activity: "the ability to go beyond the standard"; "accomplishing a task in a unique way"; "one's ability to escape common trains of thought."

Four students connected creativity to the ability to look at problems from new or multiple perspectives: "breaking down a problem/goal in as many ways as possible"; "the creative process allows for different ways of getting a solution"; "connecting pieces together in your own way"; "looking at a design from a perspective that it has not been looked at before."

Two students connected creativity to collaborative activity: "some functions were made by my coworkers but it required my creativity to combine them"; "the freedom to incorporate knowledge and expertise from various aspects of the world."

Question 2: Identify a past experience that required you to be creative.

Four students identified a work-related experience, three students identified a university course experience, and two identified recreational experiences.

Was this a positive experience?

Six students identified the experience as positive; one student was neutral; and two did not directly answer the question.

What did it teach you about your creative process?

Three students emphasized the social aspects of creativity: "a willingness to share; a willingness to let ideas go"; "the ability to work with others"; "connecting with the real world." Two students noted their ability to explore problems from more than one perspective: "breaking down a problem in multiple ways"; "looking at positives and negatives."

Question 3: Do you think creativity will be important to your future success?

All students believed creativity will be important to their success, with seven of the nine students using emphatic modifiers: "very"; "absolutely"; "vital"; "certainly"; "paramount"; "extremely"; "major."

If so, why? If not, why?

Two students stated that creativity would be important to their future success because it will allow them to improve the world. Three students stated that creativity would allow them to excel in the workplace as there are more opportunities for "creatives." One student noted that creativity will be important because there are few guidelines in the working world, and one must be creative to successfully navigate uncertain terrains.

\subsection{Video Recording Results}

I intended that the video recordings be valuable to me and to the students. If I could learn about each team's creative activities by viewing these recordings, I felt sure the students could as well.

Though I have yet to analyze these recordings in depth, I can offer preliminary observations, particularly in regard to the sequences I asked the students to view in advance of the individual interviews.

Team One November 2015: The 90-second video sequence that I asked the Team One students to view attracted me not because I specifically identified creative activity but because I identified engaged team communication that involved decision making about design options. When viewing this sequence, I made the following notes to myself about the team's activity:

- Deep concentration

- Openness and flexibility about decision making

- Teaching each other

- No rush to judgment, willingness to suspend decisions

- Good listeners

Team One January 2016: The three-minute video sequence I asked Team One students to view showed a team ready to trust one another to make important decisions. Underneath the communication there was considerable respect for each member's individual strengths. There was also a breakthrough moment, in which one student took another's idea and transformed it into something new. When viewing this sequence, I made the following notes:

- Relaxed

- Relying on each other's knowledge

- Surprise idea, eureka moment

- Building the idea together

- No rush to judgment; building together

- Mutual respect

Team Two November 2015: The 10-minute video sequence that I asked Team Two to view in advance of our interviews showed a team ready to discuss design options and willing to share ideas. Though one member initially dominated the discussion, all team members 
seemed engaged, and eventually all team members made contributions. When viewing the sequence, I made the following notes:

- All engaged, but one team member dominating

- Easy flow of ideas, little judgment

- $\quad$ Pass the stick; everyone has the opportunity to contribute

- Challenging each other for clarification, but supportively, no evident competition

\subsection{Interview Results}

Listed below are the questions I asked each student. I have yet to transcribe these files.

1. What is your engineering stream?

2. Did you view the videos? If so, how much?

3. Did you view the sections I suggested?

4. Personally, what has been your greatest accomplishment in the project?

5. Is there evidence of this in the videos?

6. Where is the evidence?

7. What is the team's greatest accomplishment in the project?

8. Is there evidence of this in the videos?

9. In the entry questionnaire that you completed back in September, you defined creativity as ...

10. Is there evidence of this in the project?

11. Is there evidence of this in the videos?

12. Has your understanding of creativity changed during the project?

13. How important has creativity been to the success of the project thus far?

14. Did you discover anything about yourself from viewing the section of the video that I recommended you view in advance?

15. Were there any surprises?

16. How would you characterize your contribution to the team discussion in this section?

17. How would you characterize the team dynamic?

18. How different is your approach in this project to the approach you took in first year?

19. Is there anything that you can take from this research project (the one I am conducting) that might help you as you move toward the end of the course?

\subsection{Exit Questionnaire Results}

I distributed the Exit Questionnaire one day after students had submitted their final course deliverable, the Portfolio. Seven of the nine participating students completed the survey. I used Survey Monkey to conduct the survey. Following are the questions I asked and the students' responses.
Question 1: Has your understanding of creativity changed as a result of your experience in APS490?

Four students answered yes, and three students answered no.

If so, how and why?

- I think the change in my definition of creativity from this course relates to how I think about creativity in teamwork. It is definitely harder to be what I would usually define as creative while in a team and that was true in this project as well.

- Yes. Creativity involves many more things than I originally thought.

- The utility of creative output is of utmost concern, not necessarily the creative process.

- Yes. Creativity could be based on interaction of multiple people.

Question 2: Approximately how much time did you spend viewing the video recordings of your team meetings?

15 minutes; 15 minutes; 25 minutes; 30 minutes; 30 minutes; 45 minutes; 3 hours.

Question 3: Was viewing the videos useful?

- Six students claimed it was useful.

- One student claimed it was not useful.

If so, explain how it was useful.

- It was useful not so much for understanding creative processes as for understanding team interactions.

- It was interesting to see my own mannerisms. Everyone has an idea how they must look to everyone else.

- It was useful to see myself. The perspective lends some insight.

- $\quad$ Yes, I could see how I behave in team meetings

- Certainly! I was able to actually see how fast I speak which is something to work on in order to communicate ideas better.

- No

Question 4: Approximately how much time did you spend listening to the audio recording of your individual interview with Professor Tallman?

- Four students did not listen to the audio recording

- One listened for one minute

- One listened for 20 minutes

- One listened for one hour

Question 5: Was it useful listening to the audio recording? If so, explain how it was useful.

- N/A

- N/A

- Yes, I can keep the audio recording as a future reference.

- Yes, it's useful to keep a copy of the recording as well as reflect on the points taken.

- I don't believe it will be since the meeting was short and uneventful. 
- Yes, I noticed that I stutter a lot, which is related to speaking fast.

Question 6: Did the video and audio recordings help you complete the APS490 Portfolio assignment?

- I did not use them directly. I think that my conversation did help me think about my priorities in the course and how to frame them in the portfolio.

- Not really, although I put very little effort into my portfolio.

- No.

- No. 1) File was too large 2) I used online portfolio, didn't want to post without my team members' agreements.

- Surely. I used the video as an evidence.

- No.

- Yes. I used the recordings to verify what are some of the highlights of the project team. And what I can improve on.

Question 7: Generally, do you think recording team meetings is a useful practice?

- Yes, but maybe not in order to better understand the creative process. They were useful to me because they allowed me to reflect and become a better communicator on my team.

- Yes, it allows you to critically examine your team meetings (which is hard to do in the moment because your mind is preoccupied) and possibly find ways to improve future meetings' productivity.

- Only as a novelty or periodically, not consistently.

- It was a good experience. I could see myself in thirdperson's view.

- $110 \%$

- No.

- Yes.

\section{SELF-ASSESSMENT OF THE PROJECT}

The research project has taken unexpected turns, and sometimes missed the intended mark, but there are promising outcomes that provide direction for future development.

As I look back on the work that began last year, I identify the following three strengths. First, requiring the students to reflect on their contributions and growth in the project, as I did, provided valuable opportunities for the students to develop self-knowledge and to practice communicating it. Though the Exit Questionnaire indicates that only two students went back and used the audio recordings of the interviews for their portfolios, I believe that the interviews were valuable to the students in themselves, providing a safe setting for the students to freely discuss their setbacks and accomplishments in the project.

Secondly, providing the students with video and audio recordings of their work proved beneficial to the students and to me. For the students, the recordings equipped them with rich, concrete data to study; for me, it provided data to study and a common point of reference for my interactions with the students. As six of the seven students verified in the Exit Questionnaire, having recordings of team meetings was useful.

Lastly, this research benefitted greatly from the multidisciplinary mix of students in the course. In the individual interviews, more than half of the students emphasized the value of learning from each other in the projects, something they felt they wouldn't have done if they had worked solely with students from their own departments. This strength, therefore, is not so much in my research approach but is a strength in the course itself. It is clear in the video recordings that the excitement and energy the students exhibit is at times the result of the learning that is taking place: they are teaching each other.

As I look back, I also identify challenges. First, recruiting student teams for a research project such as this is difficult. I did not offer students any financial compensation for participating in the project, even though some colleagues recommended I do so. Amabile stresses the importance of intrinsic motivation in fostering creative activity, offering abundant research showing that people are more creative when they are excited and passionate about what they are doing and are less creative when they are motivated by extrinsic factors, such as evaluation, reward, and competition with peers [1]. I agree with Amabile, and I worry that offering financial reward would attract the wrong type of students to a project such as this. That said, I know I need to devise more effective recruitment strategies.

The second challenge involves more clearly explaining creativity to students and then in measuring it. I am presently exploring different frameworks, including Treffinger's Four Categories of Personal Creativity Characteristics [17] (outlined above in Section 1), and Cynthia Atman's use of design process representations to assist students in learning about designing [3].

Lastly, there is the challenge of integrating faculty into this research. I have learned a great deal from the two student teams this past year, and I am certain that I would have learned just as much from faculty had they been involved. Daly's research into teaching creativity in engineering design is particularly interesting in this regard, as she interacts with students and faculty equally in her research studies [6].

\section{References}

[1] Teresa M. Amabile, "Motivating creativity in organizations: On doing what you love and loving what you do,"

California Management Review, vol. 40, no. 1, pp. 39-58, 1997.

Available as of May 7, 2016 from

www.hbs.edu/faculty/Pages/item.aspx?num=3073 
[2] Teresa M. Amabile, Regina Conti, Heather Coon, Jeffrey Lazenby, and Michael Herron, "Assessing the work environment for creativity," Academy of Management Journal, vol. 39, no. 5, pp. 1154-1184, 1996.

Available as of May 1, 2016 from

amj.aom.org/content/39/5/1154.full

[3] Cynthia J. Atman, Janet McDonnell Ryan C. Campbell, Jennifer Turns, "Students discovering their own design processes: Using design process representations to learn about designing," in Proc. 2014 IEEE Frontiers in Education Conf., (Madrid, Spain, 22-25 October, 2014), pp. $1-5$.

Available as of April 22, 2016 from

ieeexplore.ieee.org/xpls/abs_all.jsp?arnumber $=7044476$

[4] Diane F. Baker and Susan J. Baker, "To 'Catch the Sparkling Glow' : A canvas for creativity in the management classroom," Academy of Management Learning \& Education, vol. 11, no. 4, pp. 704-721, 2012. Available as of April 26, 2016 from https://www.researchgate.net/.../274693607

[5] Winslow Burleson, "Developing creativity, motivation, and self-actualization with learning systems," International Journal of Human-Computer Studies, vol. 63, pp. 436-451, 2005.

Available as of May 4, 2016 from

www.sciencedirect.com/science/article/pii/S1071581905000 467

[6] Shanna R. Daly, Erica A. Mosyjowski, and Colleen M. Seifert, "Teaching creativity in engineering courses," Journal of Engineering Education," vol. 103, no. 3, pp. 417449, 2014.

Available as of May 3, 2016 from

onlinelibrary.wiley.com > ... > Vol 103 Issue 3

[7] Margarietha J. de Villiers Scheepers and Lelani Maree, "Fostering Team Creativity in Higher Education Settings," e-Journal of Business Education \& Scholarship of Teaching, vol. 9, no. 1, pp. 70-86, 2015.

Available as of May 1, 2016 from

http://www.ejbest.org

[8] Matt Eliot and Jennifer Turns, "Constructing professional portfolios: Sense-making and professional identity development for engineering undergraduates," Journal of Engineering Education, vol.100, no. 4, pp.630-654, 2011. Available as of May 1, 2016 from onlinelibrary.wiley.com/doi/10.1002/j.21689830.2011.tb00030.../pdf

[9] John H. Flavell, "Metacognition and cognitive monitoring: A new area of cognitive-developmental inquiry," American Psychologist, vol. 34, no. 10, pp. 906-911, 1979.

Available as of April 26, 2016 from doi.apa.org/journals/amp/34/10/906.pdf

[10] Ryan A. Hargrove, "Assessing the long-term impact of a metacognitive approach to creative skill development,"
International Journal of Technology and Design Education, vol. 3, no. 3, pp. 489-517, 2013.

Available as of April 26, 2016 from

link.springer.com/article/10.1007\%2Fs10798-011-9200-6

[11] Norio Ishii, Yuri Suzuki, Hironobu Fujiyoshi, Takashi Fujii, and Masonori Kozawa, "A framework for designing learning environments fostering creativity," In A. MéndezVilas et al. (eds.) Current Developments in TechnologyAssisted Education, pp. 228-232, 2006.

Available as of April 26, 2016 from

www.scielo.br/pdf/pee/v11nspe/v11nspea06.pdf

[12] Deborah Kilgore, Brook Sattler, and Jennifer Turns, "From fragmentation to continuity: engineering students making sense of experience through the development of a professional portfolio," Studies in Higher Education, vol. 38, no. 6, pp. 807-826, 2013. Available as of May 1, 2016 from https://www.researchgate.net/.../233457932

[13] Sarnoff A. Mednick, "The associative basis of the creative process," Psychological Review, vol. 69, no. 3, pp. 220-232, 1962.

Available as of May 2, 2016 from

http://citeseerx.ist.psu.edu/viewdoc/download?doi=10.1.1.17 $0.572 \&$ rep $=$ rep $1 \&$ type $=$ pdf

[14] Matthew Newcomb, "Sustainability as a design principle for composition: Situational creativity as a habit of mind," College Composition and Communication, vol. 63, no 4, pp. 593-615, 2012.

Available as of May 1, 2016 from

www.jstor.org/stable/23264230

[15] Herbert A. Simon, "Does scientific discovery have a logic?" Philosophy of Science, vol. 40, no. 4, pp. 471-480, 1973.

Available as of May 1, 2016:

http://www.jstor.org/stable/186282?seq=1\#page_scan_tab_c ontents

[16] Dean Keith Simonton, Creativity in Science: Chance, Logic, Genius, and Zeitgeist. New York and Cambridge: Cambridge University Press, 2004, 216 pp. \{ISBN 0-52154369-X\}

[17] Donald J. Treffinger, Grover C. Young, Edwin C. Selby, and Cindy Shepardson, Assessing Creativity: A Guide for Educators, National Research Center on the Gifted and Talented, Storrs, CT, 2002

Available as of April 24, 2016 from

http://nrcgt.uconn.edu/wp-

content/uploads/sites/953/2015/04/rm02170.pdf

[18] Jennifer Turns, Cynthia J. Atman, Robin S. Adams, and Theresa Barker, "Research on engineering student knowing: Trends and opportunities," Journal of Engineering

Education, vol. 94, no. 1, pp. 27-40, 2005.

Available as of May 1, 2016 from

onlinelibrary.wiley.com/doi/10.1002/j.2168-

9830.2005.tb00827.../pdf 
Proc. 2016 Canadian Engineering Education Association (CEEA16) Conf.

[19] Jennifer Turns, Brook Sattler, and Anette Kolmos,

"Designing and refining reflection activities for engineering education," in Proc. 2014 IEEE Frontiers in Education Conf., (Madrid, Spain, 22-25 October, 2014), pp. 1-4.

Available as of May 3, 2016 from

ieeexplore.ieee.org/xpls/abs_all.jsp?arnumber $=7044250$ 